\title{
Comparison of scleral buckling and vitrectomy using wide angle viewing system for rhegmatogenous retinal detachment in patients older than 35 years
}

\author{
Sung Who Park ${ }^{1,4}$, Han Jo Kwon ${ }^{1}$, Ho Yun Kim¹', Ik Soo Byon ${ }^{2}$, Ji Eun Lee ${ }^{1,3,4^{*}}$ and Boo Sup Oum ${ }^{1}$
}

\begin{abstract}
Background: To compare scleral buckling (SB) and pars plana vitrectomy (PPV) using a wide angle viewing system (WAVS) for uncomplicated phakic rhegmatogenous retinal detachment (RRD).

Methods: The medical records of patients with uncomplicated phakic RRD were retrospectively reviewed. Eyes with pseudophakic or attached fovea were excluded. Patients treated with SB were classified as group B, and PPV using WAVS as group V. Primary success rate, visual acuity (VA), macular complications, and sustained subretinal fluid (SRF) were compared between groups.

Results: Seventy-two eyes were included in group B and 57 eyes in group V. Group B had better preoperative VA $(1.38 \pm 0.87$ vs $1.84 \pm 0.97$ in LogMAR, $P=0.010)$, but worse final VA $(0.51 \pm 0.48$ vs $0.30 \pm 0.23, P=0.012)$ than group $V$. The primary success rate of $94.7 \%$ in group $V$ was higher than $77.8 \%$ in group $B(P=0.010)$. Final success rate was $100 \%$ in both groups. There was no significant difference in macular complications between groups $(P=0.087)$. Sustained SRF was found in 22 eyes in group B (38.6 \%), while only two eyes in group V exhibited sustained SRF ( $2.8 \%$, $P<0.001$ ).
\end{abstract}

Conclusions: Pars plana vitrectomy using WAVS was more efficacious than SB for treating uncomplicated phakic RRD.

\section{Background}

Rhegmatogenous retinal detachment (RRD), which refers to detachment of the sensory retina from the retinal pigment epithelium caused by breaks in the retina, is an important cause of permanent visual loss [1]. Scleral buckling (SB) and pars plana vitrectomy (PPV) are the two major surgical treatments for RRD.

PPV was reported to be more efficacious in pseudophakic eyes [2-4], and many surgeons prefer SB in younger phakic RRD without posterior vitreous detachment (PVD) and those with less-liquefied, formed vitreous [5, 6]. Previous randomized clinical trials have showed comparable efficacy between the two

\footnotetext{
* Correspondence: jlee@pusan.ac.kr

'Department of Ophthalmology, Pusan National University Hospital, Pusan, South Korea

${ }^{3}$ Medical Institute, School of Medicine, Pusan National University, Pusan, South Korea

Full list of author information is available at the end of the article
}

surgical procedures for treating uncomplicated phakic $\operatorname{RRD}[2,5,7,8]$. Procedure choice is determined as per the surgeon's discretion in uncomplicated phakic RRD.

The safety and effectiveness of PPV has been improving owing to more technically advanced surgical instruments including a wide angle viewing system (WAVS) [9]. The WAVS enhances surgical procedures, especially for retinal detachment, because it provides comprehensive information regarding the configuration of the retinal detachment and an excellent surgical view after fluid-air exchange. Thus, the efficacy of vitrectomy for retinal detachment should be reappraised in the WAVS era.

The aim of the present study is to compare the surgical outcomes of SB and PPV using WAVS in patients with uncomplicated phakic RRD. 


\section{Methods \\ Design}

Retrospective comparative analysis of an interventional case series.

\section{Participants}

129 eyes treated with SB or PPV with WAVS for RRD were included.

The Ethical Committee of Pusan National University Hospital approved this study in accordance with the rules set forth in the Helsinki Declaration. A retrospective review was performed on the medical records of patients who underwent either SB or PPV for RRD and were followed up at least 3 months in Pusan National University Hospital from Jan. 2011 to Sep. 2013.

Patients younger than 35 years were excluded from the present study because the primary procedure in our hospital is SB for uncomplicated RRD in patients younger than 35 year-old, as our database indicates that they have a high success rate. Moreover, vitrectomy for younger patients may cause postoperative cataract progression and subsequent loss of accommodation after cataract surgery. In addition, an epidemiologic study revealed two peaks in the incidence of RRD [10], suggesting an alternative mechanism underlying the cause of PVD in younger patients [11].

RRD complicated with severe media opacity, proliferative vitreoretinopathy grade $\mathrm{C}$, posterior retinal break, or pseudophakia were defined as complicated and excluded. If the patients underwent combined PPV with SB, or had attached fovea or other ocular disease impacting visual acuity (VA), they were also excluded.

Patients treated with SB were classified as group B, while vitrectomy with WAVS was classified as group V. SB was combined with cryoretinopexy in all cases. Subretinal fluid (SRF) was drained and/or gas was injected into the vitreous cavity at each surgeon's discretion. PPV was performed using Accurus (Alcon, Fort Worth, TX, USA). The fundus was visualized using WAVS: BIOM (Oculus, Wetzlar, Germany) or Resight 700 (Carl Zeiss Meditec AG, Jena, Germany). The 23- or 25-gauge cutters were used at a rate of 2,500-5,000 cuts per minute. Cataract surgery was performed concurrently to prevent postoperative cataract progression with patient consent. If necessary to confirm the presence of PVD or epiretinal membrane (ERM), triamcinolone acetonide was applied during the PPV. For shaving peripheral vitreous, an assistant indented the sclera.

Prophylactic photocoagulation was applied only around retinal breaks or lesions predisposed to retinal detachment, not on normal looking retina. Sulfur hexafluoride $\left(\mathrm{SF}_{6}\right)$, octafluoropropane $\left(\mathrm{C}_{3} \mathrm{~F}_{8}\right)$, room air, or silicone oil were used as tamponade at the surgeon's discretion.
The baseline characteristics evaluated included age, preoperative VA, detachment area, symptoms duration, number of breaks, intraocular pressure, presence of a tear larger than 0.5 disc diameters, and presence of PVD. Detachment area was measured as clock hours at the equator. Presence of PVD was evaluated in group V during PPV.

Primary success was defined as the retina maintaining reattached for at least 3 months after the primary surgery. Localized small SRF without an increase during follow-up was not considered surgical failure. Macular complication was defined as full-thickness macular hole or ERM that required surgical intervention. Sustained submacular fluid (SMF) was defined as SRF persisting in the macula detected using spectral-domain optical coherence tomography (OCT) at 3 months or later.

Primary success rate, VA, macular complication, operation time and sustained SMF were compared between the two groups. VA, age, symptom duration, number of breaks, detachment area, intraocular pressure, operation time, and follow-up duration were compared using the Mann-Whitney $U$ test, and categorical variables, including sex, presence of tear, and primary success, macular complication, and sustained SMF using Chi-square test or Fisher's exact test. Statistical analyses were performed using IBM SPSS Statistics 21, (IBM Inc., Armonk, NY, USA) setting the level of statistical significance at $P<0.05$.

\section{Results}

A total of 129 eyes were included in the study; 72 eyes in group B and 57 eyes in group V. Four surgeons performed the operations, and no significant differences were found between their preferences or success rates. Baseline characteristics of each group are summarized in Table 1. There was no significant difference in age, sex, detachment area, intraocular pressure, or presence of a large tear between the two groups. The number of breaks was $1.5 \pm 0.9$ in group $B$, which was less than $1.9 \pm 1.2$ in group $\mathrm{V}(P=0.013)$. In only one eye $(1.8 \%)$ in group $\mathrm{V}$, the presence of vitreo-papillary adhesion was noticed during vitrectomy.

In group B, encircle, circumferential segmental buckle, and radial buckle were performed in 9 eyes (12.5\%), 62 eyes $(86.1 \%)$ and 1 eye (1.4\%), respectively. SRF was drained in 65 eyes $(90.3 \%)$. Intravitreal gas was injected in 10 eyes $(13.9 \%)$ during the operation. In group V, 46 eyes $(80.7 \%)$ underwent cataract operation concurrently. Retinotomy was performed to drain SRF in two eyes (3.5\%). $\mathrm{SF}_{6}, \mathrm{C}_{3} \mathrm{~F}_{8}$, room air, and silicone oil were used as tamponade in 36 (63.2\%), 14 (24.6\%), 3 (5.3\%), and 4 (7.0\%) eyes, respectively. And silicone oil was removed by 3 months after operation.

Primary success was achieved in 54 eyes (94.7\%) in group V, which was significantly higher than 56 eyes 
Table 1 The demographics and clinical data. Values are presented as mean \pm standard deviation

\begin{tabular}{|c|c|c|c|}
\hline & Group B & Group V & $P$-value \\
\hline Number & 72 & 57 & \\
\hline Age (Years) & $54.4 \pm 11.7$ & $56.3 \pm 9.6$ & $0.178^{*}$ \\
\hline Sex (Male/Female) & $44 / 28$ & $34 / 23$ & $1.000^{* *}$ \\
\hline Symptom duration (Days) & $21.8 \pm 46.7$ & $18.8 \pm 37.2$ & $0.978^{*}$ \\
\hline Posterior vitreous detachment (\%) & $N A^{+}$ & $98.2 \%$ & $\mathrm{NA}^{+}$ \\
\hline The number of tear $(N)$ & $1.5 \pm 0.9$ & $1.9 \pm 1.2$ & $0.013^{*}$ \\
\hline Preoperative intraocular pressure $(\mathrm{mmHg})$ & $11.5 \pm 2.5$ & $11.1 \pm 3.9$ & 0.914 \\
\hline Presence of large tear $(N, \%)$ & $58(80.6 \%)$ & $52(91.2 \%)$ & $0.133^{* * *}$ \\
\hline Initial visual acuity (LogMAR) & $1.38 \pm 0.87$ & $1.84 \pm 0.97$ & $0.010^{*}$ \\
\hline Detachment area (hours) & $6.1 \pm 2.7$ & $5.6 \pm 2.2$ & $0.186^{*}$ \\
\hline Follow up (Months) & $6.9 \pm 5.2$ & $6.6 \pm 5.1$ & $0.409^{*}$ \\
\hline
\end{tabular}

*Mann-Whitney $U$ test

**Chi square test

***: Fisher's exact test

${ }^{\dagger}$ Not applicable

$(77.8 \%)$ in group B $(P=0.010$, Fig. 1$)$. Additional procedures, including photocoagulation or intravitreal gas injection, were performed in 17 (23.6 \%) eyes in group B, which were more frequent than 3 (5.3\%) eyes in group $\mathrm{V}(P=0.009)$. Final success rate was $100 \%$ in both groups. Preoperative VA (LogMAR) in group B (1.38 \pm 0.87 ) was better than in group $\mathrm{V}(1.84 \pm 0.97, P=0.010)$, whereas visual acuity at 3 months after surgery in group B $(0.51 \pm 0.48)$ was worse than in group $\mathrm{V}$ $(0.30 \pm 0.23, P=0.012$, Fig. 2). Visual improvement in group V $(1.53 \pm 0.93)$ was significantly greater than $0.88 \pm 1.00$ in group B $(P<0.001$, Fig. 2$)$.

Three cases of macular hole and two cases of ERM required a second operation in group $B$, and one case of ERM in group $\mathrm{V}(P=0.087$, Fig. 1$)$. Sustained SMF was found in 22 eyes in group B (38.6\%), which was more common than two eyes in group V $(2.8 \% ; P<0.001$,
Fig. 1). Operation time of group B was $63.0 \pm 39.2 \mathrm{~min}$ and group $\mathrm{V}$ was $60.8 \pm 15.2$. There was no significant difference of operation time ( $\mathrm{p}=0.246)$. Two cases of redetachment were noticed after 3 months. One was noticed at 9 months after SB and the other one occurred immediately after ocular trauma at 6 months after PPV.

\section{Discussion}

The present study compared two surgical methods retrospectively for treating uncomplicated phakic RRD; PPV using WAVS was more efficacious than SB in terms of functional outcome as well as primary anatomical success.

For several decades, even after the advent of PPV in 1971 by Machemer et al. [12], SB had been the standard treatment for RRD. In recent years, evolution of surgical instruments has made PPV competitive with SB [13],

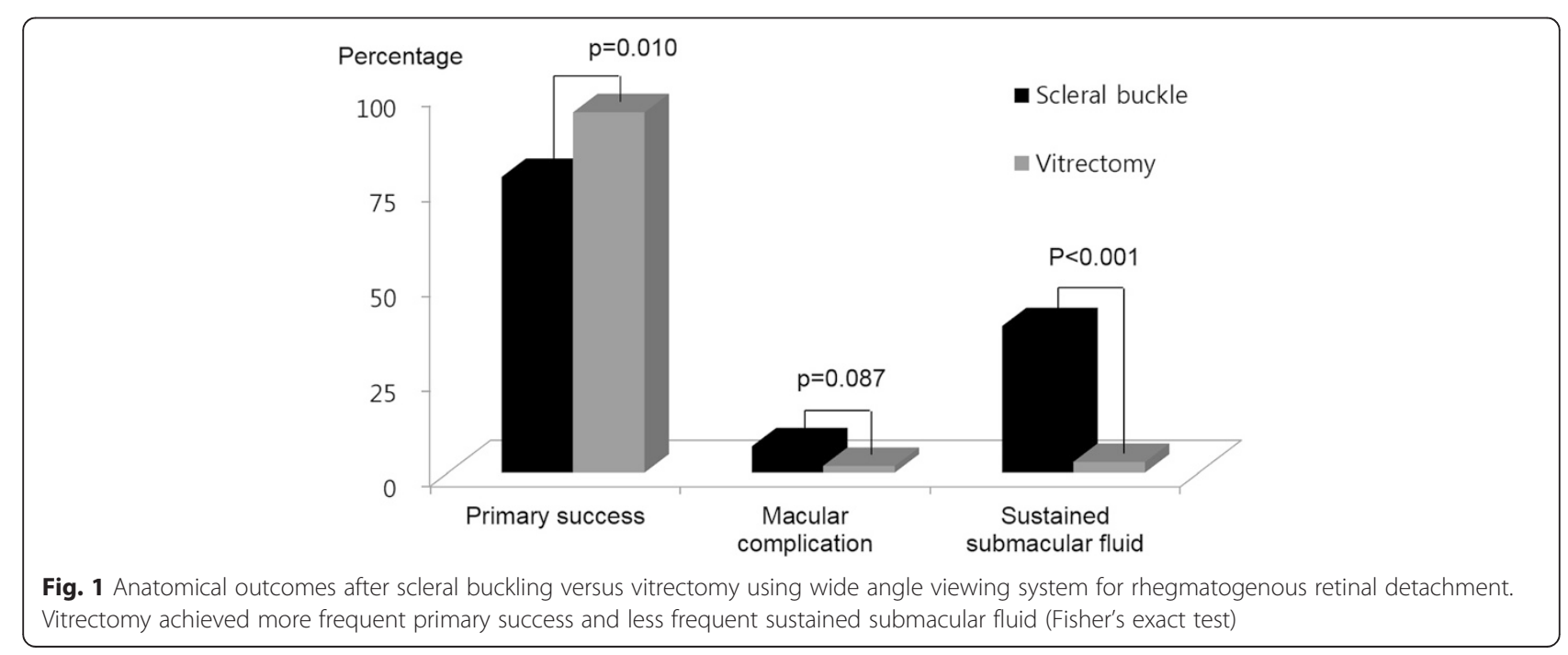




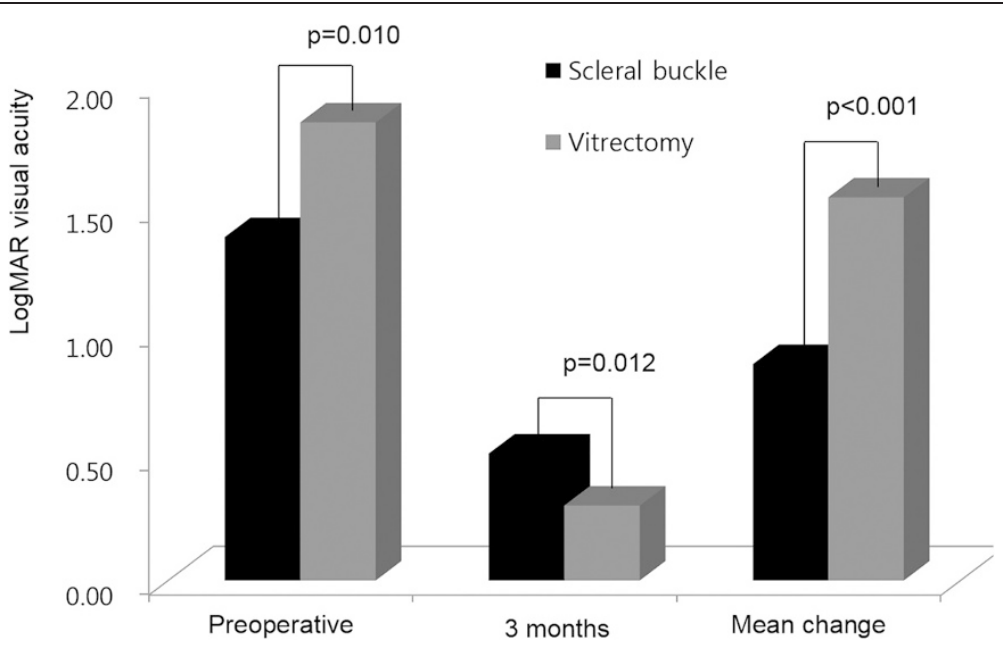

Fig. 2 Visual acuity before and after surgery between scleral buckling and vitrectomy the using wide angle viewing system

and occasionally superior to SB in specific situations, such a patients presenting with poor SB prognostic factors, such as pseudophakia $[2,14]$, media opacity, and proliferative vitreoretinopathy [6, 15-17].

Although many studies have been conducted to compare the efficacy of the two procedures prospectively or retrospectively, there is still no consensus on the optimal approach for the management of uncomplicated phakic RRD $[2,5,7,8,18,19]$. There were a few comparative data of two methods in uncomplicated phakic RRD. In 2001, Oshima et al. [18] and Miki et al. [5] compared retrospectively. In 2007 there were 3 prospective comparative studies. Koriyama et al. [7] and Azad et al. [8] evaluated in small size population, while Heimann et al. [2] conducted multicenter randomized clinical trials. In 2013, Adelman et al. [19] reported a retrospective comparative study of over 7,000 patients in 48 countries. But, they didn't show any superiority in terms of primary anatomical success.

Despite a high success rate of over $95 \%$ with PPV [6, 20] and its growing popularity, Heimann et al. [21] pointed out that this trend has not been justified by clinical results.

The superior outcome following PPV in the current study may be explained by a few characteristics that differ from previous studies. First, WAVS was used with all cases of PPV. Although not specifically mentioned, the previous studies seemed to be composed of non-WAVS or both systems. WAVS is a key advancement in vitrectomy for RRD because it enables visualization of the configuration of detachment, visualization of peripheral breaks and the macula simultaneously, and provides excellent view after fluid-gas exchange. In addition, WAVS provides a wider and better view under the presence of media opacity or small pupils [22].
Second, patients younger than 35 years old were excluded in the present study as RRD in these patients follows a different mechanism other than PVD [10]. Young patients usually have less-liquefied vitreous, and SB has a high success rate. In addition, SB may avoid cataract after vitrectomy. On the other hand, PPV in young phakic patients would be less practicable than older patients in several aspects: PVD induction and extension, and removing the peripheral vitreous.

Considering the above, the higher anatomical success rate of PPV is related to vitreous liquefaction and the presence of PVD. PVD was confirmed in $98.2 \%$ of patients during PPV the current study. More liquefied vitreous with PVD may play a role as counter action the buckle effect; this type of vitreo-retinal traction can be removed more completely by PPV than SB.

On the other hands, visual recovery was better after PPV than SB. In addition to the higher primary success rate, less frequent sustained SMF and combined cataract surgery might be the reason of better visual outcomes. Sustained SMF is observed more frequent after SB and is related to delayed visual recovery [23]. PPV is more advantageous to drain SRF completely and to achieve early reattachment.

There are several weaknesses to our study. Due to the retrospective nature of this study, patients were not randomized, and there were discrepancies in some baseline characteristics. Low initial VA and multiple breaks in group V implied the surgeons' preference for PPV in eyes with bullous RD. As all of these factors are related to poor prognosis $[24,25]$, these discrepancies might actually strengthen our results showing the superiority of PPV over SB. The other weaknesses include the short follow-up period and the small number of patients from a single center. Furthermore, 3 months of follow-up as 
inclusion criteria is relatively short to assess final visual outcome. Nevertheless, it is sufficient to assess the primary success rate and might reduce selection bias.

\section{Conclusions}

PPV is known as better option for complicated RRD, which is combined with pseudophakia [2-4], posterior retinal break or proliferative vitreoretinopathy $\mathrm{C}$. The current study showed that PPV using WAVS is more efficacious for treating not only complicated RRD but also uncomplicated than SB with respect to both functional and anatomical outcomes. Our results should be confirmed by a large scale, prospective, randomized clinical trial.

\author{
Abbreviations \\ (SB): Scleral buckling; (PPV): Pars plana vitrectomy; (WAVS): Wide angle \\ viewing system; (RRD): Rhegmatogenous retinal detachment; (VA): Visual acuity; \\ (SRF): Subretinal fluid; (PVD): Posterior vitreous detachment; (SF 6$)$ : Sulfur \\ hexafluoride; $\left(\mathrm{C}_{3} \mathrm{~F}_{8}\right)$ : Octafluoropropane; (ERM): Epiretinal membrane; \\ (SMF): Submacular fluid; (OCT): Optical coherence tomography.
}

\section{Competing interests}

The authors declare that they have no competing interests.

\begin{abstract}
Authors' contribusion
Contributors SWP was responsible for study conception and design, data acquisition, data analysis, data interpretation, and drafting the article manuscript. SWP also contributed substantially to revising of the article manuscript and approved the final version. HJK contributed to data acquisition and data interpretation. HJK approved the final version of the manuscript. HYK contributed to the study design and data acquisition. HYK approved the final version of the article manuscript. ISB contributed to the study design and was responsible for revising the article manuscript. ISB approved the final version of the article manuscript. JEL was responsible for the study and design, and contributed substantially to the data acquisition, data interpretation, and revising the manuscript. JEL approved the final version of the article manuscript. BSO contributed substantially to the study design, data acquisition, data interpretation, and was responsible for revising the article manuscript. BSO approved the final version of the article manuscript. Guarantors for the article are SWP and JEL. All authors read and approved the final manuscript.
\end{abstract}

\section{Acknowledgements}

This results were presented at Association for Research in Vision and Ophthalmology (ARVO) 2015 Annual meeting, Denver, Colorado, USA. Thanks to Han Yong Bae and Hyun Jin Park for acquiring and collecting the OCT data. OCT data.

\section{Funding}

This research received no specific grant from any funding agency in the public, commercial or not-for-profit sectors.

\section{Financial disclosure}

The authors have no property or commercial interest in any of the materials discussed in this article.

\section{Author details}

'Department of Ophthalmology, Pusan National University Hospital, Pusan, South Korea. ${ }^{2}$ Department of Ophthalmology, Pusan National University Yangsan Hospital, Yangsan, South Korea. ${ }^{3}$ Medical Institute, School of Medicine, Pusan National University, Pusan, South Korea. ${ }^{4}$ Biomedical Research Institute, Pusan National University Hospital, Pusan, South Korea.

Received: 18 June 2015 Accepted: 4 September 2015

Published online: 11 September 2015

\section{References}

1. D'Amico DJ. Clinical practice. Primary retinal detachment. N Engl J Med. 2008;359(22):2346-54. doi:10.1056/NEJMcp0804591.

2. Heimann H, Bartz-Schmidt KU, Bornfeld N, Weiss C, Hilgers RD, Foerster MH, et al. Scleral buckling versus primary vitrectomy in rhegmatogenous retinal detachment: a prospective randomized multicenter clinical study. Ophthalmology. 2007;114(12):2142-54. doi:10.1016/j.ophtha.2007.09.013.

3. Sharma YR, Karunanithi S, Azad RV, Vohra R, Pal N, Singh DV, et al. Functional and anatomic outcome of scleral buckling versus primary vitrectomy in pseudophakic retinal detachment. Acta Ophthalmol Scand. 2005;83(3):293-7. doi:10.1111/j.1600-0420.2005.00461.x.

4. Brazitikos PD, Androudi S, Christen WG, Stangos NT. Primary pars plana vitrectomy versus scleral buckle surgery for the treatment of pseudophakic retinal detachment: a randomized clinical trial. Retina. 2005;25(8):957-64.

5. Miki D, Hida T, Hotta K, Shinoda K, Hirakata A. Comparison of scleral buckling and vitrectomy for retinal detachment resulting from flap tears in superior quadrants. Jpn J Ophthalmol. 2001;45(2):187-91.

6. Schneider EW, Geraets RL, Johnson MW. Pars plana vitrectomy without adjuvant procedures for repair of primary rhegmatogenous retinal detachment. Retina. 2012;32(2):213-9. doi:10.1097/IAE.0b013e3182278b29.

7. Koriyama M, Nishimura T, Matsubara T, Taomoto M, Takahashi K, Matsumura M. Prospective study comparing the effectiveness of scleral buckling to vitreous surgery for rhegmatogenous retinal detachment. Jpn J Ophthalmol. 2007;51(5):360-7. doi:10.1007/s10384-007-0463-0.

8. Azad RV, Chanana B, Sharma YR, Vohra R. Primary vitrectomy versus conventional retinal detachment surgery in phakic rhegmatogenous retinal detachment. Acta Ophthalmol Scand. 2007;85(5):540-5. doi:10.1111/j.16000420.2007.00888.x.

9. Chalam KV, Shah VA. Optics of wide-angle panoramic viewing systemassisted vitreous surgery. Surv Ophthalmol. 2004;49(4):437-45. doi:10.1016/ j.survophthal.2004.04.010.

10. Park SJ, Choi NK, Park KH, Woo SJ. Five year nationwide incidence of rhegmatogenous retinal detachment requiring surgery in Korea. PLoS One. 2013;8(11), e80174. doi:10.1371/journal.pone.0080174.

11. Mitry D, Singh J, Yorston D, Siddiqui MA, Wright A, Fleck BW, et al. The predisposing pathology and clinical characteristics in the Scottish retinal detachment study. Ophthalmology. 2011;118(7):1429-34. doi:10.1016/ j.ophtha.2010.11.031.

12. Machemer R, Parel JM, Buettner H. A new concept for vitreous surgery. I. Instrumentation. Am J Ophthalmol. 1972;73(1):1-7.

13. Ah-Fat FG, Sharma MC, Majid MA, McGalliard JN, Wong D. Trends in vitreoretinal surgery at a tertiary referral centre: 1987 to $1996 . \mathrm{Br}$ J Ophthalmol. 1999;83(4):396-8.

14. Arya AV, Emerson JW, Engelbert M, Hagedorn CL, Adelman RA. Surgical management of pseudophakic retinal detachments: a meta-analysis. Ophthalmology. 2006;113(10):1724-33. doi:10.1016/j.ophtha.2006.05.044.

15. Gartry DS, Chignell AH, Franks WA, Wong D. Pars plana vitrectomy for the treatment of rhegmatogenous retinal detachment uncomplicated by advanced proliferative vitreoretinopathy. Br J Ophthalmol. 1993;77(4):199-203.

16. Pastor JC, Fernandez I, Rodriguez de la Rua E, Coco R, Sanabria-Ruiz Colmenares MR, Sanchez-Chicharro D, et al. Surgical outcomes for primary rhegmatogenous retinal detachments in phakic and pseudophakic patients: the Retina 1 Project-report 2. Br J Ophthalmol. 2008;92(3):378-82. doi:10.1136/bjo.2007.129437.

17. Ambresin A, Wolfensberger TJ, Bovey EH. Management of giant retinal tears with vitrectomy, internal tamponade, and peripheral $360^{\circ}$ retinal photocoagulation. Retina. 2003;23(5):622-8.

18. Oshima Y, Yamanishi S, Sawa M, Motokura M, Harino S, Emi K. Two-year followup study comparing primary vitrectomy with scleral buckling for macula-off rhegmatogenous retinal detachment. Jpn J Ophthalmol. 2000;44(5):538-49.

19. Adelman RA, Parnes AJ, Ducournau D. European Vitreo-Retinal Society Retinal Detachment Study G. Strategy for the management of uncomplicated retinal detachments: the European vitreo-retinal society retinal detachment study report 1. Ophthalmology. 2013;120(9):1804-8. doi:10.1016/j.ophtha.2013.01.070.

20. Kobashi H, Takano M, Yanagita T, Shiratani T, Wang G, Hoshi K, et al. Scleral buckling and pars plana vitrectomy for rhegmatogenous retinal detachment: an analysis of 542 eyes. Curr Eye Res. 2014;39(2):204-11. doi:10.3109/02713683.2013.838270.

21. Heimann H, Bartz-Schmidt KU, Bornfeld N, Weiss C, Hilgers RD, Foerster MH. Primary pars plana vitrectomy. Techniques, indications, and results. Der 
Ophthalmologe : Zeitschrift der Deutschen Ophthalmologischen Gesellschaft. 2008;105(1):19-26. doi:10.1007/s00347-007-1672-0.

22. Landers MB, Peyman GA, Wessels IF, Whalen P, Morales V. A new, non-contact wide field viewing system for vitreous surgery. Am J Ophthalmol. 2003;136(1):199-201

23. Benson SE, Schlottmann PG, Bunce C, Xing W, Charteris DG. Optical coherence tomography analysis of the macula after scleral buckle surgery for retinal detachment. Ophthalmology. 2007;114(1):108-12. doi:10.1016/ j.ophtha.2006.07.022.

24. Hagimura N, Suto K, lida T, Kishi S. Optical coherence tomography of the neurosensory retina in rhegmatogenous retinal detachment. Am J Ophthalmol. 2000;129(2):186-90.

25. Feltgen $\mathrm{N}$, Heimann $\mathrm{H}$, Hoerauf $\mathrm{H}$, Walter $\mathrm{P}$, Hilgers RD, Heussen $\mathrm{N}$, et al. Scleral buckling versus primary vitrectomy in rhegmatogenous retinal detachment study (SPR study): Risk assessment of anatomical outcome. SPR study report no. 7. Acta Ophthalmol. 2013;91(3):282-7. doi:10.1111/j.17553768.2011.02344.x

\section{Submit your next manuscript to BioMed Central and take full advantage of:}

- Convenient online submission

- Thorough peer review

- No space constraints or color figure charges

- Immediate publication on acceptance

- Inclusion in PubMed, CAS, Scopus and Google Scholar

- Research which is freely available for redistribution 